\title{
Twitter for teaching: can social media be used to enhance the process of learning?
}

\section{Chris Evans}

Chris Evans is a Senior Lecturer in the Brunel Business School at Brunel University. His research interests include interactivity, Web 2.0 and social media, multimedia learning technology, and the adoption of innovative learning technologies. He is Chair of the annual eLearning 2.0 international conference on social media for learning. Address for correspondence: Dr Chris Evans, Brunel Business School, Brunel University, Uxbridge, Middlesex UB8 3PH, United Kingdom.Email: Chris.Evans@brunel.ac.uk

\section{Abstract}

Can social media be used to enhance the process of learning by students in Higher Education? Social media have become widely adopted by students in their personal lives. However, the application of social media to teaching and learning remains to be fully explored. In this study, the use of the social media tool Twitter for teaching was considered. Undergraduate students in Business and Management ( $n=252)$ were encouraged to use Twitter for communicating with their tutor and each other during a twelve-week course. Their involvement was evaluated using a survey considering amount of Twitter usage and students' attitudes and experiences. The data were analysed using factor analyses, which revealed a single usage construct and three attitudinal factors. Three findings emerged. Firstly, a positive correlation was found between amount of Twitter usage and student engagement in University-associated activities including organising their social lives and sharing information. Secondly, course-related tweeting was not related to interpersonal relationships between students and their tutor. Thirdly, Twitter usage did not impact class attendance. The results are salient for educational practitioners wishing to introduce social media into their teaching.

\section{Introduction}

Enhancing the process of learning 
The changing demographic of today's students has led many educationalists to look at ways to enhance the learning process. In the past, university classes contained highly selected students, at university by choice. The dramatic expansion of Higher Education has, however, resulted in a much more diverse student population. A higher proportion of today's students now go to university not out of an academic love of the subject, but in order to gain a qualification necessary to get a job (Biggs, 1999). Such students often adopt a very different, less academic, approach to their learning, aiming to do enough to "get through" the examination. They are often characterised as surface- as opposed to deep-learners; passive rather than active learners; and, as Biggs (1999) observed, dismissed by some as unmotivated, disengaged and among those who should perhaps not be at university at all.

If, as educationalists, a more constructive conclusion is to be reached, it is necessary to accept that the task is to change the way such students learn. Biggs (1999) argued that learning outcomes should be seen more as a function of the learning process rather than fixed characteristics of the learner. It is then the tutor's job to organise the learning context so that students are more likely to adopt the learning processes which "academic" students use spontaneously. In that way our focus must be on ways in which we might enhance the learning process. Technology has come to be regarded as one of the modern tools that might be used to enhance learning (see, for example, Jisc and the Higher Education Academy, 2009). Of the most recent technological developments, social media are among the most widely experienced by the current generation of students. 
Social media are web-based or personal device-based applications that connect users with online resources or with each other. Among the best-known examples are Facebook and, more recently, Twitter. Social media have undergone an exponential growth over the last six years or so. At the time of this study, Facebook had over six hundred million and Twitter over one hundred million active users worldwide (Twopblog, 2011). Such social media have resulted in the current generation of students (termed the "Net Generation" or "Generation Y") being constantly connected. Twitter posts, for instance, can be accessed over the Web on laptops; through receiving short message service (SMS) text messages on mobile phones; and by using software applications on the growing range of smart phones. The current study considers whether this connectivity can be transferred to the process of learning and teaching in order to enhance the learning process.

\section{Social media in Higher Education}

Social media tools facilitate media and information sharing, collaboration, and participation. This makes them obvious technologies for application to Higher Education. The growing base of online educational resources includes websites, videos, podcasts, blogs, and wikis. The challenge for educationalists is to facilitate the connection between learners and relevant resources and to help learners make sense of those resources. Use of social media in Higher Education is still at an early stage and, as Junco, Heibergert and Loken (2011) note, very little empirical evidence is available concerning its impact on learning.

The two most popular social media networks are Facebook and Twitter (eBizMBA, 2013). Twitter was selected for use in the current study for three reasons. Firstly, at the time of the study the majority of the participants had no previous experience of 
using Twitter. This meant that most students had not developed preconceived ideas about the technology separate from their experience of it as a teaching tool. Therefore it was easier to evaluate Twitter in the context of teaching. Secondly, some students expressed reservations about tutors accessing their personal Facebook pages. Getting students to create separate Twitter accounts meant that they could easily maintain privacy if they wished. Thirdly, Twitter appears to lend itself better to on-going discussions with learners (Ebner, Lienhardt, Rohs \& Meyer, 2010).

Among the noteworthy preliminary studies in the use of Twitter, Ebner, Leinhardt, Rohs and Meyer (2010) tracked the use of microblogging by 34 students over a period of six weeks. They found that the average number of daily posts by each student increased from 3.5 to 5.5 as the course progressed. On average, 13 out of 53 posts per student per week were closely related to teaching and learning. The authors concluded that Twitter had great potential to expand teaching and learning beyond the classroom. Schroeder, Minocha and Schneider (2010) considered 20 social software initiatives in UK-based Higher and Further Education institutions. The authors identified several strengths and weaknesses of social media and made recommendations for educationalists. Chen and Chen (2012) conducted a study of 39 trainees who used Twitter to give feedback to their tutor after each class using direct messaging. Interviews revealed that students valued the anonymity, accessibility and connectivity it afforded.

Among the more in-depth empirical studies, Lowe and Laffey (2011) assessed the impact of using Twitter in a Marketing course by administering a five-point Likertscale survey and conducting interviews after eight weeks of usage. They asked 
questions about the perceived usefulness, enjoyment and effectiveness of Twitter. They found that take up of Twitter was good with more than $65 \%$ of their course voluntarily following the course's tweets. Using one-sample Student's $t$ tests they found that of the 46 anticipated learning outcomes surveyed, $80 \%$ were statistically different from neutrality indicating overall positive attitudes to the use of Twitter. Post hoc classification revealed that Twitter had provided: enhanced learning about the subject, greater enjoyment of the module, concise and useful communication, timeliness, greater realism, greater application of theory to real-world examples, and valuable career skills in the use of new technology. Whilst Lowe and Laffey's (2011) study revealed that perceived usefulness was a good predictor of intention to use Twitter for future courses, it did not examine the amount of Twitter usage and its relationship to student attitudes.

Johnson (2011) investigated the impact of Twitter usage on the perceived credibility of the tutor. She compared the use of social and scholarly tweets and found that participants who viewed only social tweets rated the instructor significantly higher in perceived credibility than a group that viewed only the scholarly tweets. Credibility was measured using a three-item scale relating to perceived competence, trustworthiness, and caring. The results indicated that using Twitter to share personal information increased the perceived credibility of the tutor.

Junco, Heibergert, and Loken (2011) conducted a study to see whether Twitter increases the level of engagement of students. The authors used a survey to measure broad college engagement including questions about things such as how often students attended plays or spiritual activities as well as how often students 
discussed class topics with people other than their tutor. They divided students in a 14-week health course into two groups, one of which used Twitter. The Twitter group was found to score significantly higher in the survey. This suggests that Twitter increases general student engagement. This is consistent with a previous study by Chen, Lambert and Guidry (2010) that found that the use of learning technology in general was positively related to student engagement and learning outcomes. Similar results were found in a later study by Junco, Elavsky and Heiberger (2012) in which they also found that requiring regular Twitter usage by students and staff, rather than allowing infrequent usage, increased both engagement and performance in assessment.

These studies in the use of Twitter continue the growing base of research into technology-enhanced learning. However the development of social media, and the associated creation of the Net Generation, have also had an impact on current theories about what and how people learn. Gone are the days when large amounts of information had to be memorised by individuals in order to be at their fingertips when needed. Now even larger amounts of information are accessible at the press of a key or the click of a mouse. This knowledge distribution has led some authors to advance a revised model of learning.

\section{Theoretical context}

Prior to the development of social media, the dominant learning theories were behaviourism, cognitivism and constructivism. According to Siemens (2005), the limitation of these theories is that they all posit an individualistic notion of learning. By this is meant that despite their differences, all theories consider knowledge to be located in individuals. According to Siemens, even social 
constructivism is individualistic: whilst knowledge is constructed through the process of an individual's interactions within a group, it remains located in the minds of those individuals. Connectivism (Siemens, 2005), by contrast, is based on the premise that knowledge exists in the world rather than in the mind of an individual. The theory was developed in an attempt to take account of the impact of the information revolution and the shift in importance from what an individual knows to what an individual knows how to find out through the connections they have created. As Stephenson (1998) characterised it: "I store my knowledge in my friends". This reflects the fact that people increasingly operate and make decisions not on the basis of what they know but what they can find out when they so need.

Whilst the present study does not attempt to validate Siemens's (2005) theory, it is in the spirit of the connectivist theory of learning in that it considers the experiences of a sample of learners from the Net Generation adopting a social media tool designed to facilitate connectivity. Connectivism implies that technologies that facilitate connections between people and information resources should enhance learning because knowledge is a product of these connections rather than simply what is in the head of the learner. Twitter is one such technology allowing learners to connect with each other, with tutors, and with other information resources.

\section{General methodology}

The present study considers whether the use of social media can enhance the process of learning for students in Higher Education. In particular, the aim was to investigate how the amount of Twitter usage relates to aspects of the learning process. The study adopted a survey method based on a convenience sample. 
Students undertaking a university course were encouraged to use Twitter to communicate with their tutor and each other and were later asked to evaluate this experience by completing a short survey. This approach was taken to both understand and improve the students' experience during a real course. Although distinct, the design thus has some characteristics in common with what has been referred to as "action research" (Argyris, Putnam \& Smith, 1985; Coghlan \& Brannick, 2010; Schein, 1999). It considers a real-world teaching situation rather than an artificial set-up, it involves the students as active research participants, and it aims to bring about change rather than just make observations.

The specific aim of the study was to determine how the amount of Twitter usage relates to aspects of the learning process. The interest was in quantitative aspects of Twitter usage rather than qualitative features such as type of tweets. The attitudes and experience of students in using Twitter during an undergraduate course were surveyed. Factor analysis was used to discern the key dimensions in students' attitudes and experiences. The survey also established the degree to which each student made use of Twitter and this information was correlated with the student's learning experience. The question of interest was whether the amount of Twitter usage would exhibit a positive relationship with the student experience.

\section{Method}

\section{Participants}

The participants were 252 first-year undergraduates in Business and Management at a university in London, United Kingdom. The reported age of participants ranged from 18 to 24 years, with $91 \%$ between 18 and 21, and 51\% were women. 
Design and procedure

Students who enrolled on a first-year core course in Managing Information with Technology were asked to participate in the experiment. As part of the course requirements, students were asked to set up Twitter accounts (if they did not already have one) during a laboratory session in the first two weeks of the semester. Both tutors and students were encouraged to make posts using a hashtag based on their module codes (eg. \#MG1016) during the 12 weeks of the teaching semester. Tutors were given regular suggestions for postings but were free to make whatever usage they desired. In the last two weeks participants volunteered to complete a survey anonymously during a laboratory session.

\section{Instruments}

To measure the attitudes and experiences of using Twitter, an online survey instrument was developed. The survey is shown in Table 1. There were demographic questions to identify age, gender, mode of Twitter access, type of mobile phone, and whether a Twitter account pre-existed. Other questions were included to measure the amount of Twitter usage in terms of frequency of log in, number of followers, number of people followed, and frequency of posting. The survey also included 14 Likert-scale questions using five-point agreement levels from 1 (strongly disagree) to 5 (strongly agree) measuring students' attitude and behaviour. Eight of the questions were based on instruments used in previous studies (Johnson, 2011; Lowe \& Laffey, 2011) while the remainder were specifically created for the present study (for details see Table 1). The purpose of this part of the survey was to tap into students' enjoyment and appreciation of 
Twitter usage, class attendance, tutor credibility and approachability, and perceived effectiveness for own learning.

Table 1 here

\section{Analysis}

The statistical analyses were conducted using $\operatorname{SPSS}^{\mathrm{TM}} 20$. The analyses adopted a parametric approach to Likert-scale data because of its superior power and resistance to small violations of assumptions (see eg., Kim, Park, \& Cozart, 2012; Norman, 2010; Park, Cha, Lim, \& Jung, 2013). However, because it has been argued that Likert-scale data are merely ordinal in nature (eg., Jamieson, 2004), a complementary non-parametric analysis was performed. This supplementary analysis led to the same conclusions as those reported here.

Descriptive statistics in the form of means and standard deviations were used to summarise the sample's response to each of the Likert-scale questions. The main experimental question was evaluated by creating measures for Twitter usage and the learning experience from the survey instrument data. The four questions on frequency of Twitter log in, number of followers, number of people followed and frequency of postings were all expected to measure the degree to which students used Twitter. These questions were submitted to a factor analysis to assess the validity of this assumption. A factor analysis is a commonly used statistical method to evaluate the number and identity of dimensions underlying responses to a set of questions. The approach not only provides insights into the cognitive factors that contribute to the responses, but also reduces the amount of data to avoid the excessive type I errors that may arise when each of multiple questions are 
considered in isolation. The factor analysis used here extracted underlying dimensions via principal component analysis on the correlation matrix. The same approach was used to establish the dimensions underlying the fourteen questions assessing students' attitude and behaviour. Few a priori expectations existed about the number of dimensions that would capture these questions. The Kaiser criterion was used to establish the optimal number of dimensions. This criterion eliminates factors that capture less than the variance associated with an individual question (ie., factors with eigenvalues less than one). Varimax rotation was used for multiple dimensions for optimal separation and ease of interpretation. The conceptual interpretation of the factors was based on the degree to which a survey question contributed to a factor (ie., the factor loadings). Variables with loadings larger than .6 were used to interpret a factor (MacCallum, Widaman, Preacher, \& Hong, 2001; MacCallum, Widaman, Zhang, \& Hong, 1999). A relatively high loading criterion was adopted to focus on the main contributing variables to a factor, which makes it easier to understand and label each factor. The criterion is in line with the view that loadings larger than .5 have practical significance (Hair, Anderson, Tatham \& Black, 1998). Cronbach's alpha coefficient was computed across the questions whose loadings exceeded the criterion to assess the internal consistency of a factor. In both factor analyses, the final step consisted of the computation of a student's score on each factor. These factor scores constituted the measures for Twitter usage and the learning experience. Pearson $r$ correlations were computed between these measures to determine the relationship between the two. Pairwise deletion was used to handle missing data. Factor scores were preferred over measures that only take variables with factor loadings larger than .6 into account. This is because the latter measurement method depends on the 
particular criterion that was adopted to label factors. However, an additional analysis using surrogate/composite variables rather than factor scores led to the same conclusions as those reported here.

\section{Results}

A summary of the survey data will be provided first before turning to the factor analyses that formed the basis for evaluation of the relationship between amount of Twitter usage and the learning experience. The initial description of the ways in which Twitter was accessed provides a backdrop against which to evaluate any relationship between Twitter usage and the learning experience.

\section{Description of survey data}

The survey revealed that the majority of students (46\%) used their laptop to access Twitter, 28\% used their smart phone using a Twitter application, and 19\% used a desktop computer (see Table 2). The remainder (7\%) used either a mobile web browser or SMS. Of the group as a whole, the majority were either Blackberry owners $(44 \%)$ or iPhone owners $(24 \%)$. Of the students that used their smart phone to access Twitter, $44 \%$ used a Blackberry and $40 \%$ an Apple iPhone.

Table 2 about here

Forty per cent of students already had Twitter accounts prior to the start of the study. Overall usage of Twitter was reasonable given that students were essentially early adopters in the sense that they had not previously used Twitter in an academic course. The frequencies of responses revealed that $39 \%$ of students followed more than 10 people and $34 \%$ had more than 10 followers. Twenty-seven 
per cent made more than one post per week. Twenty-four per cent logged onto Twitter at least once a day and $31 \%$ logged on less than once a month.

\section{Factor analyses}

Amount of Twitter usage. The factor analysis on the four Twitter usage questions gave rise to a single latent factor that explained $75 \%$ of the variance. The Cronbach alpha coefficient for the questions in the factor was .84 , indicating good internal consistency. The factor loadings of the questions ranged between .75 to .92 and these were used to compute a factor score as an index of the amount to which a student used Twitter.

Table 3 about here

Experience and attitudes to Twitter. The means and standard deviations of the responses to each of the 14 survey questions addressing students' attitude and behaviour are provided in Table 3. To assess the perception of Twitter for learning, the responses to the 14 questions were submitted to a factor analysis to identify the underlying constructs. A scree plot of the extracted factors is shown in Figure 1. The Kaiser criterion was employed to decide on the number of factors to consider for further analysis (note that Figure 1 merely illustrates the relative contribution of each factor and does not imply the use of a scree criterion to extract the number of relevant factors). Three factors had an eigenvalue larger than one, thus explaining more than any variable on its own. The first factor underlying the students' responses accounted for $40 \%$ of the variance, the second for $13 \%$ and the third for $8 \%$. The degree to which each survey question loaded on the three factors is shown 
in Table 4. Variables with loadings greater than .6 were used to interpret the factors (MacCallum et al., 1999, 2001) and these are highlighted in bold in Table 4.

Figure 1 and Table 4 about here

The questions that correlated more than .6 with the first factor asked about communicating with the tutor outside of class, the student-tutor boundary, tutor approachability, and the ability to interact with peers. This factor was therefore thought to define an interpersonal construct. The Cronbach's alpha coefficient for the four questions was a high .823. The second factor included questions about the effectiveness of Twitter as an instant communication tool, the enjoyment of using Twitter, and the use of Twitter for social relations. This factor may therefore tap into students' engagement in the sense of active participation in shaping their learning experience. The associated alpha coefficient was .770. The third factor contained only one question with a loading that exceeded .6. A check for internal consistency was therefore not required. This question polled the impact of Twitter on the need to be physically present in class and the associated construct must therefore be class attendance. Factor scores were calculated for each participant and these were used to determine the relationship between each of the three uncovered constructs and the degree to which Twitter was used.

\section{Relationship between Twitter usage and the learning experience}

The factor scores associated with Twitter usage on the one hand and the Engagement, Interpersonal, and Class Attendance constructs on the other were submitted to Pearson bivariate correlational analysis. A significant positive correlation was found between Twitter usage and Engagement, $\mathrm{r}(235)=.55$, 
$\mathrm{p}<.001$. The size of the effect $(.55)$ is considered to be large (Cohen, 1988), meaning that $30 \%$ of the total variance is shared by the two variables. This correlation indicates that the more a student made use of Twitter, the more they actively participated in shaping their experience (or vice versa). In contrast, no associations were found between Twitter usage and the Interpersonal construct, $\mathrm{r}(235)=.05, \mathrm{p}=.46$, or the Class Attendance construct, $\mathrm{r}(235)=.01, \mathrm{p}=.83$.

\section{Discussion}

The aim of this study was to determine whether social media can be used to enhance the process of learning by students in Higher Education. A group of business students used Twitter in the process of their learning for a period of 12 weeks and their experience and attitudes were evaluated using a survey. Factor analysis revealed three dimensions to their answers: interpersonal relations, engagement and class attendance. Further analysis showed that the amount that students used Twitter could account for some attitudes but not others. While Twitter usage showed a positive correlation with the degree to which students engaged in course-related activities such as social exchanges and sharing information, Twitter usage was not associated with interpersonal relations or class attendance. Thus, Twitter usage had a selective impact on factors related to the learning experience and its influence can therefore not easily be explained by general motivation. This is important because it helps to identify the precise contribution that social media can make to the process of learning. The role of each of the three emergent dimensions is discussed in detail below.

\section{Does using Twitter improve interpersonal relations?}


The correlation coefficient between amount of Twitter usage and the Interpersonal construct was close to zero, suggesting that there is no relationship between the two. Using Twitter for teaching does thus not in itself improve the relationship between a tutor and learners. The results indicate that the Interpersonal construct was composed of questions that asked about communicating with the tutor outside class, breaking the boundaries between students and tutors, and tutor approachability. The last two questions were derived from the study by Johnson (2011), which investigated the effect of Twitter on perceptions of instructor credibility. Johnson found that when Twitter was used for social communication it increased the credibility of tutors relative to its use for scholarly communication. Students who viewed purely social tweets from their tutor rated tutors significantly higher on a measure of credibility than the group that viewed only scholarly tweets. No significant difference was found between either of these groups and a third group that viewed a mixture of social and scholarly tweets. Johnson's (2011) study did not include a comparison between the use of scholarly tweets and no Twitter usage. This means that it is difficult to evaluate the effect of scholarly tweets alone. Taken together with the findings from the current study, it may be proposed that the use of scholarly Tweets has no impact on students' perceptions of their relationship with the tutor. In turn, this may mean that the content of tweets can have a differential impact on the learning process. Tutors whose aim is to improve credibility may therefore need to focus on social tweets. In contrast, those who wish to use Twitter as a teaching tool should be aware that it is unlikely to contribute to breaking down barriers between students and the tutor. Further studies of the learning process are needed to determine whether social tweets alone or also in combination with scholarly tweets impact learner performance. More 
generally, a fruitful area for future research would be to discern the role of qualitative aspects of tweets in the learning experience. In particular, it would be useful to consider categorising tweets as, for example, administrative, social or scholarly and to investigate the effects of each.

\section{Does using Twitter increase student engagement?}

The present study found a strong relationship between Twitter usage and student engagement as indicated by a Pearson coefficient of .55. Students who used Twitter more were more likely to indicate that they engaged in Universityassociated activities including organising their social lives, sharing personal information and posting their thoughts. The relationship between the two variables explained a respectable $30 \%$ of the variance. The positive relationship is consistent with the study by Junco et al. (2011) who found that found that Twitter usage increased overall student engagement including curricular activities (eg., participation in class discussions or discussions with an instructor) and extracurricular activities (eg., attending a play or participating in a spiritual activity). As is true for all correlational analyses, it is not possible to identify the direction of any causal relationship. It may be that increasing Twitter usage causes an increase in engagement, or that students who are more engaged will make greater use of Twitter. Whilst either relationship is of practical value, it is of theoretical interest to establish the direction of causality. The study by Junco et al. (2011) may suggest that Twitter usage causes increased engagement. If this is the case, the introduction of Twitter may be a way to increase the general level of engagement and reduce the number of students who become disengaged in a course, thus enhancing the overall learning process. The alternative conclusion is that it is through the process 
of engaging with Twitter that students find it to be a tool they want to continue using.

\section{Is Twitter usage linked to attendance?}

Many tutors are concerned that the adoption of social media tools that allow communication outside the classroom will cause a detrimental reduction in classroom attendance. The presumption is that learning can only happen in the classroom and that reduced attendance is indicative of a reduction in learning. Regardless of the validity of this assumption, student ratings in the present study indicated that they considered it unlikely that Twitter made it any less necessary to attend classes (Table 3). Moreover, there was no relationship between Twitter usage and class attendance as indicated by a Pearson correlation that was close to zero and statistically non-significant. In other words, frequent users of Twitter showed no tendency to attend fewer classes than other students.

The findings are perhaps best understood in the light of the connectivist theory of learning. From a connectivist perspective the process of learning is enhanced by anything that increases the connections between students and each other and also between students and online resources. The increase in engagement related to Twitter usage is indicative of the contribution made by connectivity. However, the findings could also be explained by social constructivist theory because it was the social rather than academic relations that proved to be important. The current study was not designed to distinguish between these educational theories and further work is needed to investigate the effect of Twitter from each of these theoretical perspectives. 


\section{Conclusions}

This study set out to determine whether social media can be used to enhance the process of learning by students in Higher Education. Three results emerged from the investigation. Firstly, the amount of Twitter usage was associated with increased student engagement including organising their social lives and sharing information. Secondly, course-related tweeting showed no evidence of being related to interpersonal relations between students and their tutor. Thirdly, Twitter usage also did not relate to class attendance. The findings are important for educational practitioners as they suggest ways in which social media might impact teaching. The selective impact of Twitter usage suggests ways in which the medium might best be exploited to increase connections between students themselves, students and their tutors, and students and educational resources. In particular, it appears that using Twitter is an effective way to engage students, and tutors need not fear that it will result in a drop in attendance at lectures or seminars. The choice between making educational tweets as opposed to personal tweets should be made carefully as they have different effects on the way tutors are perceived by students. It would be of considerable interest for future studies to assess which aspects of the learning process can be improved by Twitter and social media more generally.

\section{Acknowledgements}

This research was supported by Brunel University's Information Systems Evaluation and Integration Research Group. The author would like to thank Afaf Buqawa for help with conducting the study. 


\section{References}

Argyris, C., Putnam, R. \& Smith, M. (1985). Action science: concepts, methods and skills for research and intervention. San Francisco, USA: Jossey-Bass.

Biggs, J. (1999). What the student does: teaching for enhanced learning. Higher Education Research and Development, 18, 1, 57-75.

Chen, L. \& Chen, T-L. (2012). Use of Twitter for formative evaluation: reflections on trainer and trainees' experiences. British Journal of Educational Technology, $43,2,49-52$.

Chen, P. S. D., Lambert, A. D. \& Guidry, K. R. (2010). Engaging online learners: the impact of web-based learning technology on college student engagement. Computers \& Education, 54, 1222-1232.

Coghlan D. \& Brannick T. (2010). Doing action research in your own organization ( $3^{r d}$ ed.). London, England: Sage.

Cohen, J. (1988). Statistical power analysis for the behavioural sciences $\left(2^{\text {nd }}\right.$ ed.). Hillsdale, NJ: Lawrence Erlbaum.

Ebner, M., Lienhardt, C., Rohs, M. \& Meyer, I. (2010). Microblogs in higher education - a chance to facilitate informal and process-oriented learning. Computers \& Education, 55, 92-100.

eBizMBA (2013). Top 15 most popular social networking sites: July 2013. Retrieved from http://www.ebizmba.com/articles/social-networking-websites

Hair, J. F. Jr., Anderson, R. E., Tatham, R.L. \& Black, W.C. (1998). Multivariate data analysis $\left(5^{\text {th }}\right.$ ed.). Upper Saddle River, NJ: Prentice Hall.

Jamieson, S. (2004). Likert scales: how to (ab)use them. Medical Education, 38, $12,1217-1218$. 
Jisc and the Higher Education Academy (2009). Enhancing learning through technology. Retrieved from http://www.jisc.ac.uk/media/documents/publications/enhancinglearningthrought echnology.pdf

Johnson, K.A. (2011). The effect of Twitter posts on students' perceptions of instructor credibility. Learning, Media and Technology, 36, 1, 21-38.

Junco, R., Elavsky, C. M. \& Heiberger, G. (2012). Putting Twitter to the test: assessing outcomes for student collaboration, engagement and success. British Journal of Educational Technology, 44, 273-287. doi: 10.1111/j.14678535.2012.01284.x

Junco, R., Heibergert, G. \& Loken (2011). The effect of Twitter on college student engagement and grades. Journal of Computer Assisted Learning, 27, 119-132.

Kim, C., Park, S. W. \& Cozart, J. (2012). Affective and motivational factors of learning in online mathematics courses. British Journal of Educational Technology, advance online publication 13 December 2012.

doi: $10.1111 / \mathrm{j} .1467-8535.2012 .01382 . x$

Lowe, B. \& Laffey, D. (2011). Is Twitter for the birds? Using Twitter to enhance student learning in a marketing course. Journal of Marketing Education, 33, 2, 183-192.

MacCallum, R. C., Widaman, K. F., Zhang, S. \& Hong, S. (1999). Sample size in factor analysis. Psychological Methods, 4, 84-99.

MacCallum, R. C., Widaman, K. F., Preacher, K. J. \& Hong, S. (2001). Sample size in factor analysis: the role of model error. Multivariate Behavioural Research, 36, 611-637.

Norman, G. (2010). Likert scales, levels of measurement and the "laws" of 
statistics. Advances in Health Science Education, 15, 5, 625-632.

Park, S. Y., Cha, S.-B., Lim, K. \& Jung, S.-H. (2013). The relationship between university student learning outcomes and participation in social network services, social acceptance and attitude towards school life. British Journal of Educational Technology, advance online publication 3 July 2013. doi: 10.1111/bjet.12013

Schein, E. H. (1999). Process consultation revisited: building the helping relationship. Reading, MA: Addison-Wesley.

Schroeder, A., Minocha, S. \& Schneider, C. (2010). The strengths, weaknesses, opportunities, and threats of using social software in higher and further education teaching and learning. Journal of Computer Assisted Learning, 26, $159-174$

Siemens, G. (2005). Connectivism: a learning theory for the digital age. International Journal of Instructional Technology and Distance Learning, 2, 1. Retrieved from http://www.itdl.org/Journal/Jan_05/article01.htm

Stephenson, K. (1998). What knowledge tears apart, networks make whole. Internal Communication Focus, 36. Retrieved from http://www.netform.com/html/icf.pdf

Twopblog (2011). What does 300 million registered Twitter accounts mean? Retrieved from http://www.twopblog.com/2011/05/what-does-300-millionregistered.html 